\title{
BMJ Open Here one year, gone the next? Investigating persistence of frequent emergency department attendance: a retrospective study in Australia
}

\author{
Luise Lago, ${ }^{\oplus}$ Victoria Westley-Wise, ${ }^{1,2}$ Judy Mullan, ${ }^{1}$ Kelly Lambert, ${ }^{1}$ \\ Rebekah Zingel, ${ }^{3}$ Thomas Carrigan, ${ }^{4}$ Wayne Triner, ${ }^{4}$ Kathy Eagar ${ }^{5}$
}

To cite: Lago L, WestleyWise V, Mullan J, et al. Here one year, gone the next? Investigating persistence of frequent emergency department attendance: a retrospective study in Australia. BMJ Open 2019;9:e027700. doi:10.1136/ bmjopen-2018-027700

- Prepublication history and additional material for this paper are available online. To view these files, please visit the journal online (http://dx.doi org/10.1136/bmjopen-2018027700).

Received 8 November 2018 Revised 15 May 2019 Accepted 22 May 2019

Check for updates

(C) Author(s) (or their employer(s)) 2019. Re-use permitted under CC BY-NC. No commercial re-use. See rights and permissions. Published by BMJ.

For numbered affiliations see end of article.

Correspondence to

Dr Luise Lago;

lago@uow.edu.au

\section{ABSTRACT}

Objectives Patients are presenting to emergency departments (EDs) with increasing complexity at rates beyond population growth and ageing. Intervention studies target patients with 12 months or less of frequent attendance. However, these interventions are not well targeted since most patients do not remain frequent attenders. This paper quantifies temporary and ongoing frequent attendance and contrasts risk factors for each group.

Design Retrospective population-based study using 10 years of longitudinal data.

Setting An Australian geographic region that includes metropolitan and rural EDs.

Participants 332100 residents visited any ED during the study period.

Main outcome measure Frequent attendance was defined as seven or more visits to any $E D$ in the region within a 12-month period. Temporary frequent attendance was defined as meeting this threshold only once, and ongoing more than once. Risk factors for temporary and ongoing frequent attenders were identified using logistic regression models for adults and children.

Results 0 f 8577 frequent attenders, $80.1 \%$ were temporary and $19.9 \%$ ongoing (12.9\% repeat, $7.1 \%$ persistent). Among adults, ongoing were more likely than temporary frequent attenders to be young to middle aged (aged 25-64 years), and less likely to be from a high socioeconomic area or be admitted. Ongoing frequent attenders had higher rates of non-injury presentations, in particular substance-related $(\mathrm{OR}=2.5,99 \% \mathrm{Cl} 1.1$ to 5.6$)$ and psychiatric illness $(\mathrm{OR}=2.9,99 \% \mathrm{Cl} 1.8$ to 4.6$)$. In comparison, children who were ongoing were more likely than temporary frequent attenders to be aged 5-15 years, and were not more likely to be admitted $(\mathrm{OR}=2.7,99 \% \mathrm{Cl}$ 0.7 to 10.9 ).

Conclusions Future intervention studies should distinguish between temporary and ongoing frequent attenders, develop specific interventions for each group and include rigorous evaluation.

\section{INTRODUCTION}

\section{Background}

Emergency department (ED) frequent attenders are a complex and vulnerable

\section{Strengths and limitations of this study}

- Our unique, longitudinal data platform has enabled this study on long-term patterns of attendance to all emergency departments (EDs) within a single geographic region by frequent attenders over 10 years.

- We considered long-term frequent attendance patterns, which allowed for patients discontinuing frequent attendance and resuming later on.

- We contrasted sociodemographic and risk factors for temporary versus ongoing frequent attendance and for both adults and children.

- We included metropolitan, regional and rural EDs in Australia; however, findings from one healthcare setting may not be generalisable to other settings.

patient group. ${ }^{1-4}$ Compared with non-frequent ED attenders, they have higher rates of morbidity and mortality, ${ }^{5}$ mental health issues $^{5-7}$ substance use problems ${ }^{6}{ }^{8}$ and chronic diseases, ${ }^{8-10}$ and are more likely to be homeless ${ }^{11}$ and of low socioeconomic status. ${ }^{12}$ By definition, this group accounts for a disproportionate share of ED visits. They are also more likely to attend multiple EDs to address their unmet health needs. ${ }^{8}$

Interventions are primarily aimed at reducing ED visits, ${ }^{13-17}$ and improving social and clinical outcomes. ${ }^{13} 1618$ The most commonly studied intervention is case management. ${ }^{10} 131618$ Other interventions include establishment of care plans with patient input, ${ }^{19}$ and providing case notes from previous $\mathrm{ED}$ visits. ${ }^{20}$ Case management in some cases reduced ED costs and improved social and clinical outcomes, but in many studies had no impact, or increased ED and primary care utilisation. ${ }^{13}$ The limited number of studies with control groups has contributed to a lack of evidence on effective interventions, as before-and-after studies fail 
to account for the high likelihood of frequent attenders becoming infrequent without intervention. ${ }^{1}$

\section{Relevance}

Few studies have investigated long-term use patterns among ED attenders across multiple facilities. ${ }^{21}$ Most studies report data from a single year, ${ }^{22-28}$ or a small number of years, ${ }^{11} 16$ or from a small number of facilities, ${ }^{9} 2930$ with ongoing visit patterns given little consideration. ${ }^{1}$ Multisite studies of $>2-3$ years are scarce. ${ }^{121} 3132$ The need for research into long-term utilisation patterns among frequent attenders has been identified, in particular understanding predictors of ongoing use,${ }^{21}$ and analysis by age group and frequency of visit, to distinguish meaningful subgroups for intervention. ${ }^{133}$

Research addressing these knowledge gaps will assist with identifying and distinguishing the characteristics of ongoing frequent attenders from those with temporary frequent ED use. This information will assist in planning appropriate support or interventions for the temporary and ongoing subgroups of frequent attenders.

\section{Objectives}

The aim of this study was to contrast the attributes and risk factors of temporary frequent attenders, with ongoing frequent attenders. The ongoing frequent attenders were further subdivided into repeat frequent attenders, who met the frequent attendance threshold twice, and persistent frequent attenders, who met the threshold in three or more periods.

\section{METHODS}

\section{Study design and setting}

A retrospective population-based study was carried out using longitudinal data from an Australian regional health service, the Illawarra Shoalhaven Local Health District (ISLHD). The district services almost 390000 residents in a $250 \mathrm{~km}$ long coastal catchment area, covering rural, regional and metropolitan areas. ${ }^{34}$ Five of the eight public hospitals within the district have an ED, the largest being one of the busiest adult and paediatric EDs in the state of New South Wales. ${ }^{35}$

\section{Selection of participants}

This negligible risk study accessed data from the Illawarra Health Information Platform (IHIP). IHIP is a non-identifiable databank established by the ISLHD and the University of Wollongong for research, planning and evaluation purposes. IHIP holds a unique record number for every person who has accessed any ISLHD service since the late 1980s. ED data were analysed for all individuals who attended any of the district's EDs at least once between 1 July 2005 and 30 June 2015. Non-residents of the district's catchment area were excluded.

\section{Ethical approval}

The study involved the use of existing non-identifiable data sourced from ISLHD routine administrative data and accessed from IHIP. An executive steering committee includes senior representatives of both institutions including the Chief Executive and Director of Research at ISLHD, and the Deputy Vice-Chancellor Research at UOW. The committee, as the institutional review board, deemed the study exempt from ethical review, as it was negligible risk, involved only routinely collected non-identifiable data that had already been approved by the HREC, and were already stored in IHIP, used only unlinked data, and did not require any further approvals (eg, specific ethics approval from the Aboriginal Health and Medical Research Council). This study was completed in accordance with the National Statement on Ethical Research 2007 (updated 2018, The National Health and Medical Research Council, the Australian Research Council and Universities Australia) and the Helsinki Declaration (as revised in 2013).

\section{Patient and public involvement}

Previous studies by the authors on patient's reasons for attending $\mathrm{ED},{ }^{36}$ and other literature on patient perspectives in the $\mathrm{ED},{ }^{37}$ shaped the research questions, including a focus on understanding long-term use patterns rather than individual visits. The retrospective study was designed to inform future interventions and research. While patients were not directly involved in the design or conduct of this study, a steering group that includes a patient advisor will contribute to research translation and dissemination activities. Dissemination to patients will also occur through the health district's Community Partnership Council and other established patient advisory committees.

\section{Outcomes}

The primary outcome of the study was an estimate of the proportion of frequent attenders for whom frequent attendance is a temporary phenomenon (occurring only once during the study period). A secondary outcome was to identify and contrast risk factors for temporary and ongoing frequent attendance to highlight characteristics associated with continuing frequent ED use.

\section{Measurements}

Historically, frequent ED use has been defined as 3-12 visits per year, ${ }^{5}$ while highly frequent use has been defined as 4-20 visits per year. ${ }^{78}$ Because of this variation, Locker et al proposed that more than four ED visits per year was a non-random event, and suggested this become a standard threshold for defining frequent ED attendance. ${ }^{6}$ This study uses a more recently proposed definition based on a divergence of patient characteristics, where non-frequent attenders present one to six times in a year, and frequent attenders seven or more times in a year. ${ }^{39}$ A subgroup of highly frequent attenders, ${ }^{39}$ who made 18 or more visits to EDs in any 12-month period, were also investigated.

A 12-month window was used to count ED visits following a first (or index) ED visit, a patient-based timeline not defined by calendar year. ${ }^{39} 40$ Subsequent 
12-month windows commenced at the next ED visit after each 12-month window. Consequently, a subsequent period of frequent attendance was not constrained to immediate following a first period.

Duration of frequent ED attendance was measured by the number of 12-month windows each patient had frequent ED use. Subgroups of frequent attenders were identified to provide insight into the varying needs of this complex and heterogeneous patient group. Temporary frequent attenders were defined as those who met the frequent attendance threshold once during the study period, and ongoing frequent attenders were looked at in two groups-repeat frequent attenders who met the threshold twice, and persistent frequent attenders, who met the threshold three or more times.

Demographic characteristics such as age, sex, preferred language and marital status were analysed according to the first ED visit in the study period. Private hospital insurance status and Aboriginal and Torres Strait Islander status were analysed according to the most recent visit to the $\mathrm{ED},{ }^{41}$ due to a higher proportion of missing data in the early study years. Triage category was averaged over all visits with an average of 4-5 considered low urgency. The proportion of all ED visits resulting in a hospital admission was calculated for each person.

Socioeconomic status was based on Index of Relative Socioeconomic Disadvantage (IRSD) information. ${ }^{42}$ Each Australian postal area has an IRSD score and ranking. For the purposes of this study, the rankings which were summarised as deciles were reduced to quintiles, with low ranks representing the most disadvantaged.

Patient diagnosis was recorded on discharge from the ED. Between 2009 and 2012 each ED within the regional health service transitioned from International Classification of Diseases, Ninth Revision, Clinical Modification (ICD-9-CM) diagnosis coding to Systematized Nomenclature of Medicine Clinical Terms (SNOMED CT) recording of diagnosis. For this study, diagnoses according to ICD-9-CM coding and SNOMED were therefore mapped to International Statistical Classification of Diseases and Related Health Problems, Tenth Revision, Australian Modification (ICD-10-AM) ${ }^{43}$ and then aggregated to major diagnostic blocks (MDBs) using the Independent Hospital Pricing Authority's Urgency Related Group software V.1.4.4. ${ }^{44}$ Frequent ED attenders were primarily analysed according to their most common MDB to reduce the likelihood of bias from with missing data (such as during system transition and for patients who did not wait), but also described based on whether they ever had a diagnosis in each MDB.

\section{Data analysis}

Associations between categorical variables were evaluated using Pearson's $\chi^{2}$ test. Multivariate mixed logistic regression models with crossed random effects to control for attendance at one or more ED's were used to identify factors associated with frequent attendance among persistent, repeat and temporary groups, each compared with non-frequent attenders. Results were summarised as OR and CI presented with alpha of 5\% adjusted for multiple comparisons via Bonferroni correction according to the number of model parameters estimated in each model. This resulted in odds ratios with $99.8 \%$ CIs for models relating to adults, and $99.6 \%$ relating to children (where less model parameters were used). Demographic, diagnosis (MDB) and visit characteristics were included in regression models. The proportion of missing data was generally low, ranging from $<1 \%$ for items such as sex, Aboriginal or Torres Strait Islander status, socioeconomic status and triage category, to 5.3\% for preferred language, $10.8 \%$ for hospital insurance and $11.4 \%$ for marital status. Those without an assigned MDB due to; no recorded diagnosis (7.5\%), a diagnosis code not recognised by the grouper $(3.9 \%)$ or patients who did not wait $(3.5 \%)$, were excluded from analysis by diagnosis. Planned return visits accounted for $3.1 \%$ of all ED visits, and these were excluded from all analyses. Sensitivity analyses were carried out with an alternative threshold for frequent ED attendance of four visits per year, and including planned return visits. Statistical significance was set at $5 \%$. All statistical analysis was conducted using SAS V.9.4. ${ }^{45}$ Multilevel logistic models with crossed random effects were fit using PROC GLIMMIX with model fit, discrimination and calibration assessed using $\chi^{2} / \mathrm{DF}$, area under the curve and Hosmer-Lemeshow $\chi^{2}$, respectively.

\section{RESULTS}

A total of 1199633 ED visits by 332100 individuals were recorded across the 10-year study period (table 1). Of residents who attended the $\mathrm{ED}, 2.6 \%(\mathrm{n}=8577)$ met the threshold for frequent attendance (attended seven or more times within a 12-month window).

Among frequent attenders, most $(\mathrm{n}=6866,80.1 \%)$ met the attendance threshold only once (temporary frequent attenders) (figure 1). A further 12.9\% ( $\mathrm{n}=1104)$ met the threshold twice (repeat frequent attenders), while only $7.1 \%(\mathrm{n}=607)$ met the threshold on three or more occasions (persistent frequent attenders). Over the 10 years, these 607 persistent frequent attenders made 38338 ED visits. A similar pattern of predominantly temporary frequent attendance was observed in each age group (figure 1).

A sensitivity analysis including planned return visits indicated similar patterns of long-term ED use. For example, $81.4 \%$ of frequent attenders were temporary frequent attenders when planned return visits were included. When the threshold of frequent attendance was reduced to four visits in 12 months, $75.6 \%$ of individuals were temporary frequent attenders.

\section{Demographic and visit characteristics}

Compared with non-frequent attenders, frequent attenders were more likely to be male, older (aged 65 years or over), Aboriginal or Torres Strait Islander, have no 
Table 1 Characteristics of ED patients, 12-month windows and visits* by length of frequent attendance

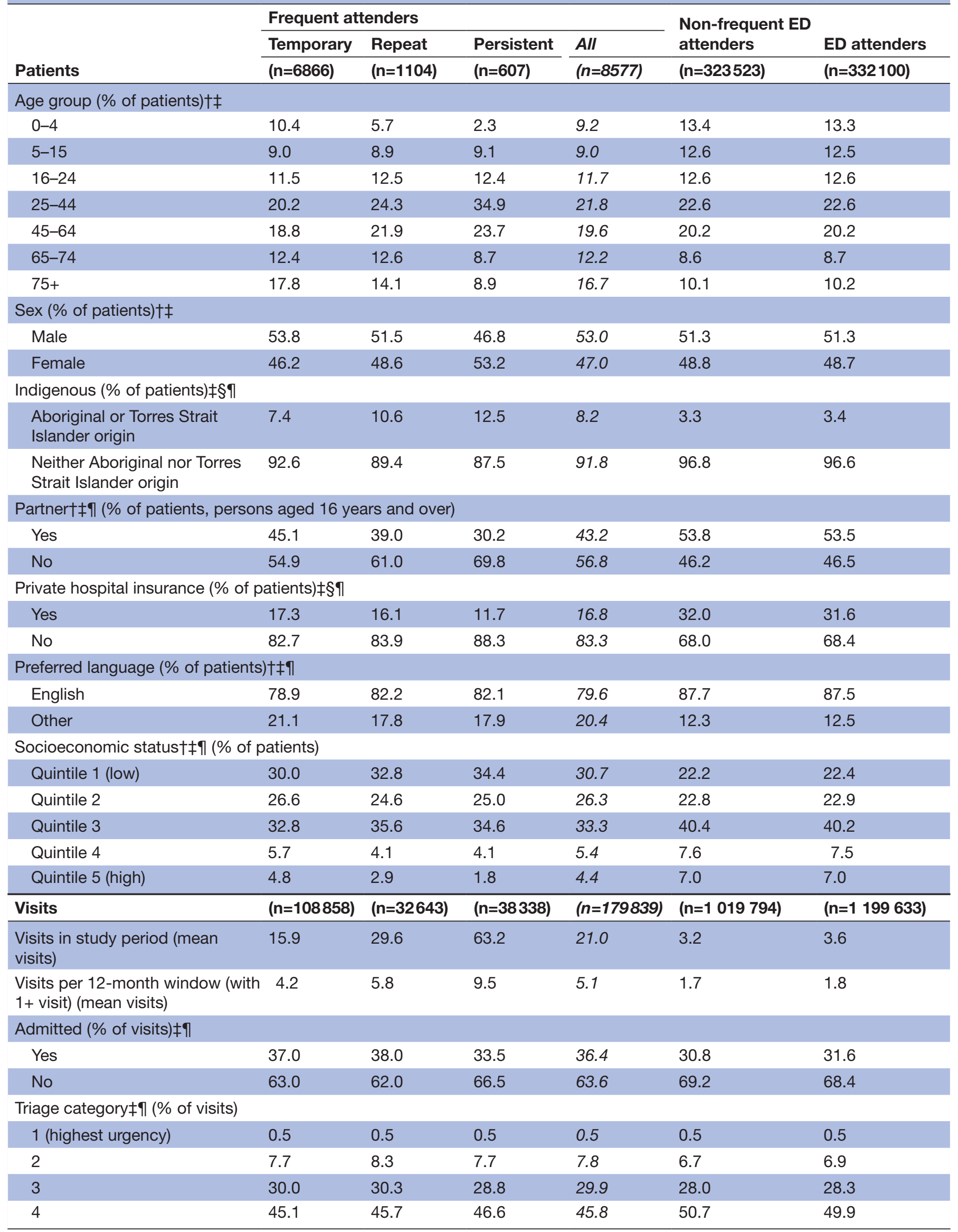


Table 1 Continued

\begin{tabular}{lllllll}
\hline Visits & $(\mathrm{n}=\mathbf{1 0 8 8 5 8 )}$ & $\mathbf{( n = 3 2 6 4 3 )}$ & $\mathbf{( n = 3 8 3 3 8 )}$ & $\mathbf{( n = 1 7 9 8 3 9 )}$ & $\mathbf{( n = 1 0 1 9} \mathbf{7 9 4})$ & $(\mathbf{n}=\mathbf{1} 199633)$ \\
\hline 5 (lowest urgency) & 16.7 & 15.3 & 16.4 & 16.7 & 14.2 & 14.5 \\
\hline
\end{tabular}

${ }^{*}$ Excludes planned return visits.

†As reported at earliest ED visit in study period.

$\mp \chi^{2}$ test for patient type (temporary frequent attender, repeat frequent attender, ongoing frequent attender by: age $\chi^{2}=164.5$ ( $p<0.0001$ ), sex $12 \chi_{2}^{2}=12.2(p=0.002)$, Indigenous $\chi_{2}^{2}=29.1(p<0.0001)$, partner $\chi_{2}^{2}=43.8(p<0.0001)$, hospital insurance $\chi_{2}^{2}=10.8(p=0.045)$, preferred language $\chi_{2}^{2}=8.6(p=0.014)$, socioeconomic status $\chi_{8}^{2}=34.6(p<0.0001)$, admitted $\chi_{2}^{2}=196.7(p<0.0001)$, triage category $\chi_{8}^{2}=76.0(p<0.0001)$. Excludes unknown, missing and not-stated.

$\S A s$ reported at most recent ED visit in study period. This is the recommended approach for Indigenous status ${ }^{41}$ and was required for hospital insurance due to incomplete early data at two facilities.

१Percentage missing, unknown, not stated-partner $11.5 \%$, Indigenous status (at last ED visit) $0.9 \%$, socioeconomic status $0.0 \%$, hospital insurance (at last ED visit) $10.8 \%$, preferred language $5.3 \%$, admitted $0.0 \%$, triage category $0.2 \%$.

ED, emergency department.

partner, from non-English speaking backgrounds, uninsured (publically insured only patients) and resident in lower socioeconomic areas (table 1). Compared with the other groups of frequent attenders, persistent frequent attenders were young to middle aged adults, female, Aboriginal or Torres Strait Islander, had no partner, were from lower socioeconomic areas, uninsured (publically insured only patients) and not admitted (table 1 ). During the 10-year study period, frequent attenders had an average of $21.0 \mathrm{ED}$ visits, compared with 3.2 for non- frequent attenders, with more frequent attenders admitted to hospital.

\section{Diagnostic profile}

The most common diagnoses among frequent attenders were digestive, respiratory, circulatory, single site major injury and psychiatric illness (online supplementary table 1 ); however, diagnostic profile differed by age and length of frequent attendance.

Among the youngest frequent attenders, aged 0-4 years, respiratory illness was the most common diagnosis across all groups' frequent attenders (table 2). Among children aged 5-15 years, injury and digestive system illnesses were the two most common diagnoses in all subgroups, with injury being the most common diagnosis among temporary frequent attenders and digestive system illness among the persistent frequent attenders. Children also presented with psychiatric illness, which was the most common diagnosis for $9.3 \%$ of temporary frequent attenders, $14.3 \%$ of repeat frequent attenders and $12.7 \%$ of persistent frequent attenders.

While injury and digestive system illness were also common among older teenagers and young adults (16-24 and 25-44 years), there were increasing numbers of patients visiting ED primarily for psychiatric illness, particularly among repeat frequent attenders aged 25-44 years and persistent frequent attenders (table 2).

Among adults aged 45-64 years, the most common diagnoses were circulatory, digestive and respiratory illnesses. Among older adults 65 years and above, circulatory followed by respiratory system illnesses were most common, with the exception of persistent frequent attenders who had more respiratory illness than circulatory illness. In the older age groups, aged 75 years and above, digestive system and urological system illness were common among all frequent attender groups.
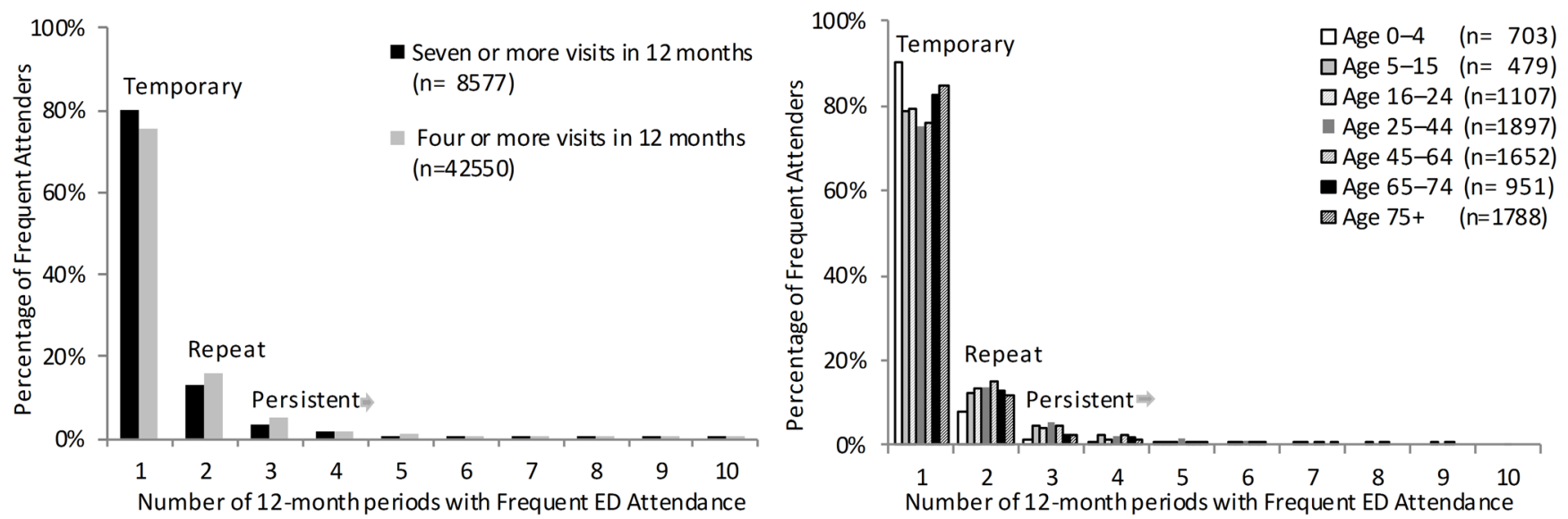

Figure 1 Number of 12-month periods where the frequent attendance threshold was met by frequently attending residents. Left: all residents with seven or more visits in 12 months and all residents with four or more visits in 12 months. Right: all residents with seven or more visits in 12 months by age group. Excludes planned return visits. ED, emergency department. 


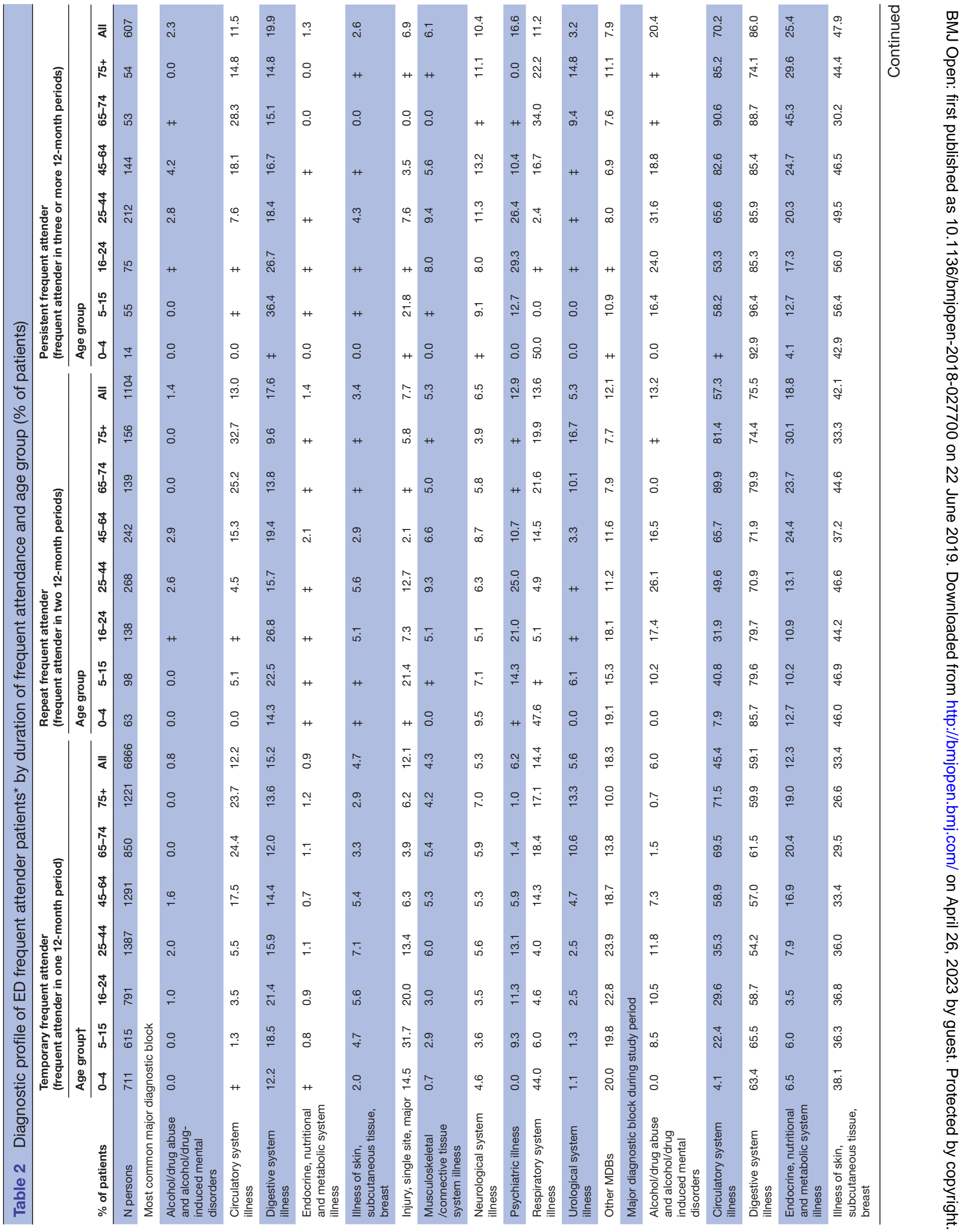




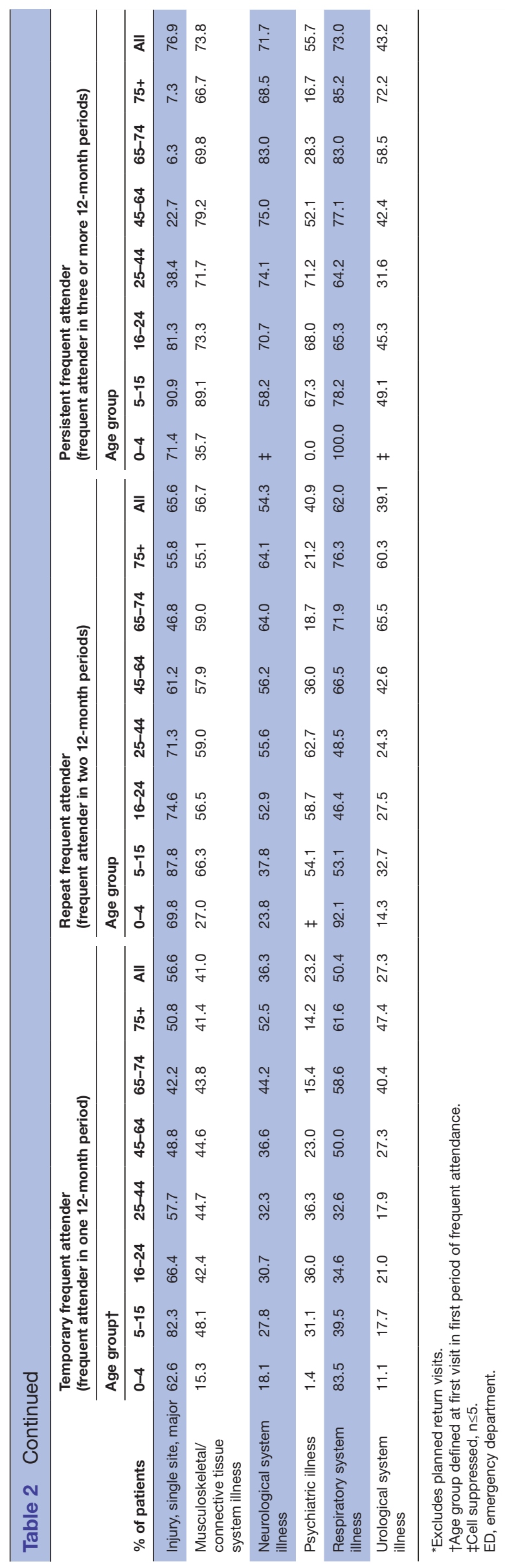

Analysis of all diagnoses reported in the study period (rather than most common) shows that from the age of 25 years, ED visits relating to single site major injuries were common among temporary and repeat frequent attenders, while persistent frequent attenders had higher proportions of respiratory, musculoskeletal, neurological and psychiatric visits (table 2). Among ongoing frequent attenders aged 5-15, 16-24 and 25-44 years, more than half presented with a psychiatric diagnosis at least once during the study period.

\section{Risk factors associated with frequent attendance}

Multivariate multilevel logistic regression models with crossed random effects were fit to assess the likelihood of being a frequent attenders, based on sociodemographic and visit characteristics and diagnoses for those aged 16 years and over (table 3 ) and those aged under 16 years (table 4). Consistent with the findings of the earlier descriptive analysis, being an adult frequent attender was associated with being: male; older; Aboriginal or Torres Strait Islander; uninsured (publically insured only patients); socioeconomically disadvantaged; presenting with higher urgency; lower likelihood of admission; and less likely to have a partner (table 3). Compared with the reference category (single site major injury), frequent attendance was associated with all diagnostic groups, with the highest odds of psychiatric illness $(\mathrm{OR}=6.2,99 \% \mathrm{CI}$ 5.1 to 7.5$)$ and alcohol/drug-related disorders $(\mathrm{OR}=6.4$, 99\% CI 4.3 to 9.7 ) (table 3 ).

Among children aged under 16 years, frequent attenders were more likely to be older (aged $5-15$ years) and similar to adult frequent attenders, were more likely to be Aboriginal or Torres Strait Islander, uninsured (publically insured only patients); socioeconomically disadvantaged; and present with higher urgency $(\mathrm{OR}=2.3,99 \% \mathrm{CI}$ 1.9 to 2.9 ). However, they were not more likely to be male; and were no less likely to be admitted than non-frequent attenders (table 4).

Compared with the reference category (single site major injury), frequently attending children aged under 16 years were more likely to present with digestive illness, neurological system illness and respiratory illness. As with adults, the highest risk of frequent attendance was presenters with psychiatric illness (OR=6.7, 99\% CI 4.1 to 11.1) (table 4).

\section{Risk factors associated with frequent attendance by duration}

Models fitted separately for each frequent attendance subgroup (temporary frequent attenders compared with non-frequent, repeat frequent attenders compared with non-frequent and persistent frequent attenders compared with non-frequent attenders) led to different demographic risk factors. While temporary adult frequent attenders were more likely to be male, after adjusting for other characteristics, sex was not a risk factor for repeat $(\mathrm{OR}=1.2,99 \% \mathrm{CI} 1.1$ to 1.3$)$ or persistent frequent attenders ( $\mathrm{OR}=1.0,99 \%$ CI 0.7 to 1.2$)$ (table 3). Persistent adult frequent attenders were also more likely to be in 
Table 3 Logistic regression modelling characteristics associated with frequent attendance: non-frequent versus (1) all frequent attenders, (2) temporary frequent attenders, (3) repeat frequent attenders and (4) persistent frequent attenders. Persons aged 16 years or over

\begin{tabular}{|c|c|c|c|c|}
\hline & $\begin{array}{l}\text { Non-frequent } \\
\text { vs all frequent } \\
\text { attenders* }\end{array}$ & $\begin{array}{l}\text { Non-frequent vs } \\
\text { temporary frequent } \\
\text { attenders } t\end{array}$ & $\begin{array}{l}\text { Non-frequent vs } \\
\text { repeat frequent } \\
\text { attenders } \ddagger\end{array}$ & $\begin{array}{l}\text { Non-frequent vs } \\
\text { persistent frequent } \\
\text { attenders }\end{array}$ \\
\hline Variable & OR (Cl) & OR (Cl) & OR (Cl) & OR (Cl) \\
\hline \multicolumn{5}{|l|}{ Sex } \\
\hline Male & $1.2(1.1$ to 1.3$)$ & $1.2(1.1$ to 1.3$)$ & $1.2(1.0$ to 1.5$)$ & $0.9(0.7$ to 1.2$)$ \\
\hline Female (reference) & 1.0 & 1.0 & 1.0 & 1.0 \\
\hline 16-24 (reference) & 1.0 & 1.0 & 1.0 & 1.0 \\
\hline $25-44$ & 1.2 (1.0 to 1.3$)$ & 1.1 (1.0 to 1.3$)$ & 1.6 (1.1 to 2.3$)$ & 1.9 (1.2 to 3.0$)$ \\
\hline $45-64$ & $1.4(1.2$ to 1.6$)$ & 1.3 (1.1 to 1.5$)$ & 2.0 (1.3 to 2.9$)$ & 2.4 (1.5 to 3.9$)$ \\
\hline $65-74$ & 1.8 (1.5 to 2.1$)$ & 1.6 (1.4 to 2.0$)$ & $2.2(1.4$ to 3.4$)$ & 2.1 (1.1 to 3.8$)$ \\
\hline No (reference) & 1.0 & 1.0 & 1.0 & 1.0 \\
\hline \multicolumn{5}{|l|}{ Uninsured (no private hospital insurance) } \\
\hline Yes & 1.7 (1.6 to 1.9$)$ & 1.7 (1.5 to 1.9$)$ & 1.8 (1.3 to 2.4$)$ & 1.9 (1.2 to 2.8$)$ \\
\hline No (reference) & 1.0 & 1.0 & 1.0 & 1.0 \\
\hline \multicolumn{5}{|l|}{ Aboriginal or Torres Strait Islander } \\
\hline Yes & $2.0(1.7$ to 2.4$)$ & 1.9 (1.5 to 2.3$)$ & $2.5(1.7$ to 3.7$)$ & 2.6 (1.6 to 4.2$)$ \\
\hline No (reference) & 1.0 & 1.0 & 1.0 & 1.0 \\
\hline \multicolumn{5}{|l|}{ High average triage (1-3) } \\
\hline Yes & 2.1 (1.9 to 2.3$)$ & 2.0 (1.8 to 2.3$)$ & 2.4 (1.8 to 3.2$)$ & 1.9 (1.3 to 2.7$)$ \\
\hline \multicolumn{5}{|l|}{ Socioeconomic status } \\
\hline Quintile 1 (low) & $1.4(1.2$ to 1.5$)$ & $1.4(1.2$ to 1.5$)$ & $1.3(1.0$ to 1.7$)$ & $1.4(1.0$ to 2.0$)$ \\
\hline Quintile 2 & $0.9(0.8$ to 1.0$)$ & 0.9 (0.8 to 1.1$)$ & 0.9 (0.6 to 1.2$)$ & 0.8 (0.5 to 1.3$)$ \\
\hline Quintile 3 (reference) & 1.0 & 1.0 & 1.0 & 1.0 \\
\hline Quintile 4 & $0.6(0.5$ to 0.8$)$ & 0.7 (0.6 to 0.9$)$ & 0.5 (0.3 to 0.8$)$ & $0.5(0.2$ to 1.1$)$ \\
\hline Quintile 5 (high) & $0.6(0.5$ to 0.7$)$ & 0.7 (0.5 to 0.8$)$ & $0.4(0.2$ to 0.7$)$ & 0.3 (0.1 to 0.8$)$ \\
\hline \multicolumn{5}{|l|}{ Major diagnostic block†† } \\
\hline $\begin{array}{l}\text { Alcohol/drug abuse and alcohol/ } \\
\text { drug-induced mental disorders }\end{array}$ & 6.4 (4.3 to 9.7$)$ & 5.1 (3.2 to 8.2) & 11.2 (4.4 to 28.3$)$ & $17.9(6.2$ to 51.5$)$ \\
\hline Circulatory system illness & 2.3 (1.9 to 2.7$)$ & 2.0 (1.7 to 2.5$)$ & 3.4 (2.0 to 5.5$)$ & $4.0(2.0$ to 8.0$)$ \\
\hline Digestive system illness & 2.8 (2.4 to 3.3$)$ & 2.5 (2.1 to 3.0$)$ & $4.3(2.7$ to 7.0$)$ & 5.6 (2.9 to 10.6$)$ \\
\hline $\begin{array}{l}\text { Endocrine, nutritional and metabolic } \\
\text { system illness }\end{array}$ & 2.8 (1.9 to 4.2$)$ & $2.4(1.5$ to 3.7$)$ & 4.8 (1.8 to 13.1$)$ & 6.5 (1.7 to 24.4$)$ \\
\hline $\begin{array}{l}\text { Illness of skin, subcutaneous tissue, } \\
\text { breast }\end{array}$ & $2.9(2.4$ to 3.7$)$ & $2.9(2.2$ to 3.6$)$ & 3.6 (1.9 to 7.0$)$ & 2.7 (1.0 to 7.3$)$ \\
\hline Injury, single site, major (reference) & 1.0 & 1.0 & 1.0 & 1.0 \\
\hline
\end{tabular}




\begin{tabular}{|c|c|c|c|c|}
\hline & $\begin{array}{l}\text { Non-frequent } \\
\text { vs all frequent } \\
\text { attenders* }\end{array}$ & $\begin{array}{l}\text { Non-frequent vs } \\
\text { temporary frequent } \\
\text { attenders } \dagger\end{array}$ & $\begin{array}{l}\text { Non-frequent vs } \\
\text { repeat frequent } \\
\text { attenders } ¥\end{array}$ & $\begin{array}{l}\text { Non-frequent vs } \\
\text { persistent frequent } \\
\text { attenders } \S\end{array}$ \\
\hline Variable & OR (Cl) & OR (Cl) & OR (Cl) & OR (Cl) \\
\hline $\begin{array}{l}\text { Musculoskeletal/connective tissue } \\
\text { system illness }\end{array}$ & 1.7 (1.4 to 2.1$)$ & 1.5 (1.2 to 1.9$)$ & 2.6 (1.5 to 4.7$)$ & 3.1 (1.4 to 6.7$)$ \\
\hline Neurological system illness & 2.2 (1.8 to 2.7$)$ & 1.8 (1.4 to 2.3$)$ & $3.2(1.8$ to 5.8$)$ & 6.8 (3.3 to 13.7$)$ \\
\hline Respiratory system illness & 3.3 (2.8 to 4.0$)$ & $3.0(2.4$ to 3.6$)$ & 5.1 (3.1 to 8.5$)$ & $5.6(2.8$ to 11.4$)$ \\
\hline Urological system illness & 3.2 (2.6 to 3.9$)$ & 3.0 (2.4 to 3.8$)$ & 4.3 (2.3 to 7.8$)$ & 3.4 (1.3 to 8.6$)$ \\
\hline Other & 1.7 (1.4 to 1.9$)$ & $1.6(1.4$ to 2.0$)$ & $1.8(1.1$ to 3.0$)$ & $1.3(0.6$ to 2.8$)$ \\
\hline
\end{tabular}

${ }^{*} \mathrm{n}=211447, \mathrm{AUC}=0.82$, Hosmer-Lemeshow $\chi^{2}=1867(\mathrm{p}<0.0001)$, generalised $\chi^{2} / \mathrm{DF}=0.90$.

$\dagger \mathrm{n}=210198, \mathrm{AUC}=0.80$, Hosmer-Lemeshow $\chi^{2}=1461(\mathrm{p}<0.0001)$, generalised $\chi^{2} / \mathrm{DF}=0.90$

$\ddagger \mathrm{N}=206440, \mathrm{AUC}=0.87$, Hosmer-Lemeshow $\chi^{2}=877(\mathrm{p}<0.0001)$, generalised $\chi^{2} / \mathrm{DF}=0.79$.

$\S \mathrm{N}=206$ 097, $\mathrm{AUC}=0.89$, Hosmer-Lemeshow $\chi^{2}=678(\mathrm{p}<0.0001)$, generalised $\chi^{2} / \mathrm{DF}=0.89$.

१Missing values imputed with patient's most recent non-missing value.

††Most frequent MDB over all visits. Excludes missing diagnoses and those unable to be mapped to an MDB. All MDBs which included less than five ongoing, repeat or temporary frequent attenders was included with 'Other MDB' in a category labelled 'Other'.

$99.8 \% \mathrm{Cl}(\alpha$ adjusted for multiple comparisons, $1-\alpha / \mathrm{m}=1-0.05 / 26=0.998)$.

AUC, area under the curve.

the middle age groups, aged 25-44 years. Among those aged under 16 years, repeat frequent attenders were more likely to be female and aged $5-15$ years $(\mathrm{OR}=0.6$, $99 \%$ CI 0.3 to 1.0 ), which was the same OR for persistent attenders $(\mathrm{OR}=0.6,99 \% \mathrm{CI} 0.2$ to 1.4$)$, though not statistically significant after adjustment for multiple comparisons (table 4).

Demographic and clinical risk factors for adult frequent attendance were in many cases magnified among repeat and persistent frequent attenders (table 3). For example, Aboriginal or Torres Strait Islander background was a larger risk factor for those with long periods of frequent attendance (temporary frequent attenders $\mathrm{OR}=1.9$, 99\% CI 1.5 to 2.3 and persistent frequent attenders $\mathrm{OR}=2.6,99 \%$ CI 1.6 to 4.2 ) and having a partner was less likely among longer duration frequent attenders (temporary frequent attenders $\mathrm{OR}=0.7,99 \% \mathrm{CI} 0.7$ to 0.8 and persistent frequent attenders $\mathrm{OR}=0.5,95 \% \mathrm{CI} 0.4$ to 0.7 ).

Alcohol and drug-related disorders were much more prominent among longer-duration frequent attenders (temporary frequent attenders OR=5.1, 99\% CI 3.2 to 8.2 compared with persistent frequent attenders $\mathrm{OR}=17.9$, 99\% CI 6.2 to 51.5), as were neurological illness (temporary frequent attenders $\mathrm{OR}=1.8,99 \%$ CI 1.4 to 2.3 compared with persistent frequent attenders $\mathrm{OR}=6.8$, 99\% CI 3.3 to 13.7), and psychiatric illness (temporary frequent attenders $\mathrm{OR}=4.8,99 \%$ CI 3.8 to 6.0 compared with persistent frequent attenders $\mathrm{OR}=13.7,99 \%$ CI 7.1 to 26.5) (table 3).

\section{Risk factors for temporary versus ongoing frequent} attendance

Risk factors for the ongoing frequent attender group (repeat and persistent combined) were modelled in comparison to temporary frequent attenders. This confirmed the earlier findings that ongoing frequent attenders are younger (aged 25-64 years) but less likely to have be admitted, or be from high socioeconomic areas (figure 2, left image). Substance-related visits, psychiatric illness and neurological illness were again more likely for ongoing frequent attenders. Among children aged under 16 years, ongoing frequent attenders were more likely than temporary frequent attenders to be aged 5-15 years (figure 2, right image). Highly frequent users (18 or more visits in any 12-month period) were more likely to be ongoing frequent attenders. Among those who only met the lower frequent attendance threshold (7-17 visits in a 12 -month period), $5.1 \%$ were persistent frequent attenders. In contrast, of patients who met the highly frequent threshold at least once (18 or more visits in any 12 -month period), $45.5 \%$ were persistent frequent attenders.

\section{DISCUSSION}

This investigation of 10 years of longitudinal ED data has provided a novel perspective on the risk factors by duration of frequent attenders, for both adults and children. Investigation of visits to all EDs in the region found the majority of frequent ED attenders are temporary and only $\sim 20 \%$ remain as frequent attenders in any of up to nine subsequent years. Persistent frequent attenders only accounted for $7.1 \%$ of frequent attenders. This did not vary when the threshold was reduced from seven down to four visits in 12 months, or when planned return visits were included in the analyses. 
Table 4 Logistic regression modelling characteristics associated with frequent attendance: non-frequent versus (1) all frequent attenders, (2) temporary frequent attenders, (3) repeat frequent attenders and (4) persistent frequent attenders. Persons aged under 16 years

\begin{tabular}{|c|c|c|c|c|}
\hline \multirow[b]{2}{*}{ Variable } & \multirow{2}{*}{$\begin{array}{l}\text { Non-frequent vs all } \\
\text { frequent attenders* } \\
\text { OR (Cl) }\end{array}$} & \multirow{2}{*}{$\begin{array}{l}\text { Non-frequent vs } \\
\text { temporary frequent } \\
\text { attenders† } \\
\text { OR (Cl) }\end{array}$} & \multirow{2}{*}{$\begin{array}{l}\text { Non-frequent vs } \\
\text { repeat frequent } \\
\text { attenders } \$ \\
\text { OR }(\mathrm{CI})\end{array}$} & \multirow{2}{*}{$\begin{array}{l}\text { Non-frequent vs } \\
\text { persistent frequent } \\
\text { attenders§ } \\
\text { OR (CI) }\end{array}$} \\
\hline & & & & \\
\hline \multicolumn{5}{|l|}{ Sex } \\
\hline Male & $0.9(0.8$ to 1.1$)$ & $1.0(0.8$ to 1.2$)$ & $0.6(0.3$ to 1.0$)$ & $0.6(0.2$ to 1.4$)$ \\
\hline Female (reference) & 1.0 & 1.0 & 1.0 & 1.0 \\
\hline 0-4 (reference) & 1.0 & 1.0 & 1.0 & 1.0 \\
\hline $5-15$ & 1.0 (0.8 to 1.2$)$ & $1.0(0.8$ to 1.1$)$ & $1.4(0.8$ to 2.4$)$ & $1.3(0.5$ to 3.1$)$ \\
\hline \multicolumn{5}{|l|}{ Uninsured (no private hospital insurance) } \\
\hline Yes & 1.8 (1.4 to 2.2$)$ & 1.8 (1.4 to 2.2$)$ & 1.7 (0.8 to 3.4$)$ & $2.3(0.7$ to 7.9$)$ \\
\hline No (reference) & 1.0 & 1.0 & 1.0 & 1.0 \\
\hline \multicolumn{5}{|l|}{ High average triage (1-3) } \\
\hline Yes & 2.3 (1.9 to 2.9$)$ & 2.3 (1.8 to 2.8$)$ & $2.5(1.2$ to 4.9$)$ & 4.7 (1.1 to 19.1$)$ \\
\hline No (reference) & 1.0 & 1.0 & 1.0 & 1.0 \\
\hline Proportion of visits admitted & 0.9 (0.7 to 1.3$)$ & 0.9 (0.6 to 1.3) & 1.3 (0.5 to 3.5) & $1.6(0.3$ to 8.2$)$ \\
\hline \multicolumn{5}{|l|}{ Socioeconomic status } \\
\hline Quintile 1 (low) & 1.7 (1.4 to 2.0$)$ & 1.6 (1.3 to 2.0$)$ & 2.1 (1.2 to 3.6$)$ & 2.3 (0.9 to 5.8$)$ \\
\hline Quintile 2-5 (reference) & 1.0 & 1.0 & 1.0 & 1.0 \\
\hline \multicolumn{5}{|l|}{ Major diagnostic block ${ }^{\star \star}$} \\
\hline Other & $0.9(0.7$ to 1.1$)$ & 0.9 (0.7 to 1.2$)$ & 1.2 (0.5 to 2.7$)$ & 1.4 (0.3 to 6.5$)$ \\
\hline
\end{tabular}

${ }^{*} \mathrm{n}=82$ 344, AUC=0.83, Hosmer-Lemeshow $=456(p<0.0001)$, generalised $\chi^{2} / \mathrm{DF}=0.87$.

$\dagger \mathrm{n}=82115, \mathrm{AUC}=0.82$, Hosmer-Lemeshow $=415(\mathrm{p}<0.0001)$, generalised $\chi^{2} / \mathrm{DF}=0.85$.

$\ddagger \mathrm{N}=80$ 958, $\mathrm{AUC}=0.87$, Hosmer-Lemeshow $=158(\mathrm{p}<0.0001)$, generalised $\chi^{2} / \mathrm{DF}=0.88$.

$\S \mathrm{n}=80$ 867, AUC $=0.93$, Hosmer-Lemeshow $=64(\mathrm{p}<0.0001)$, generalised $\chi^{2} / \mathrm{DF}=0.64$.

ПMissing values imputed with patient's most recent non-missing value.

${ }^{* *}$ Most frequent MDB over all visits. Excludes missing diagnoses and those unable to be mapped to an MDB. All MDBs which included less than five ongoing, repeat or temporary frequent attenders was included with 'Other MDB' in a category labelled 'Other'.

$\mathrm{Cl}(\alpha$ adjusted for multiple comparisons, $1-\alpha / \mathrm{m}=1-0.05 / 12=0.996)$.

AUC, area under the curve.

The estimate that $80.1 \%$ of frequent attenders are temporary is slightly higher than other shorter-term studies carried out in the USA, ${ }^{1334346}$ Sweden $^{3}$ and New Zealand, ${ }^{47}$ where estimates varied between $58 \%$ and $72 \%$. Definitions of temporary frequent attenders differ slightly across studies, including the threshold number of visits for frequent attenders; whether the period of frequent attendance is patient-based (using an index visit) or calendar based; whether another period of frequent attendance immediately follows the first frequent attendance period or is during the study period. We considered any periods of frequent attendance across the entire study period, to be inclusive of patients who re-established frequent attendance patterns. ${ }^{48}$

Systematic reviews show that internationally, intervention studies have been targeting the entire frequent attender cohort. ${ }^{1314}$ However, differences in profile and risk factors for ongoing frequent attenders compared 

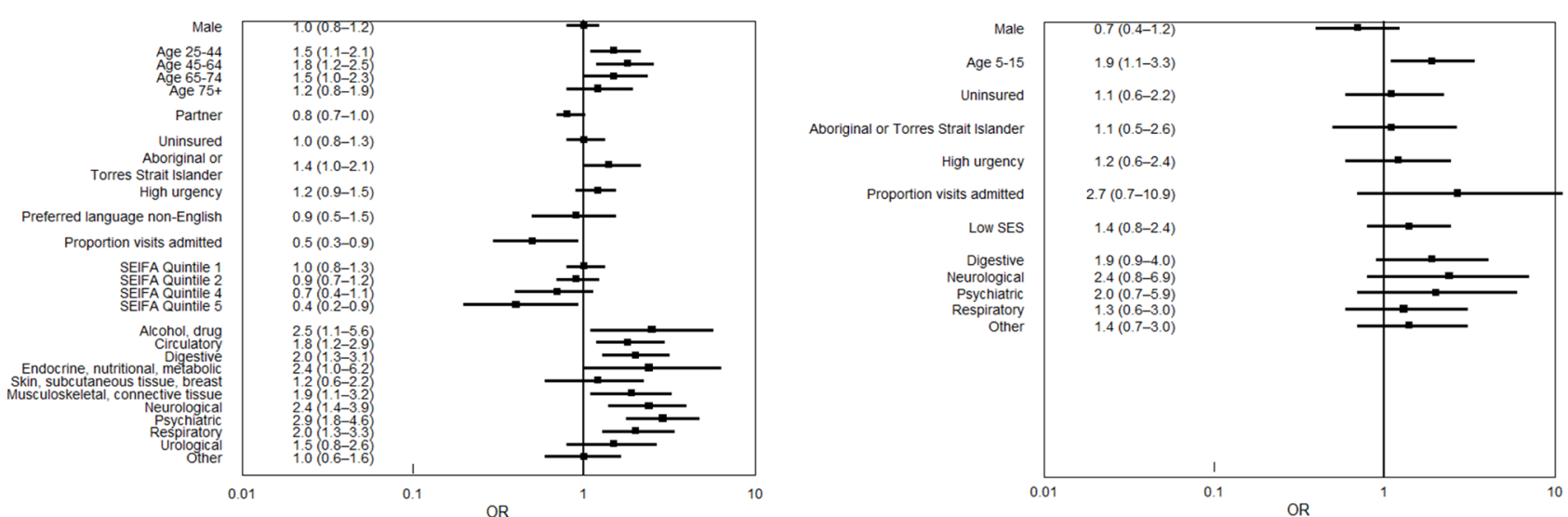

Figure 2 Logistic regression model identifying characteristics associated with ongoing versus temporary frequent attendance. Left: persons aged 16 years and over $(n=5803)$. Right: persons aged under 16 years $(n=1546)$. Reference categories for persons aged 16 years and over-age: 16-24 years, SEIFA: quintile 3, major diagnostic block: single site major injury. Reference categories for persons aged under 16 years-age: 0-4, SEIFA: quintile 2-5, major diagnostic block: single site major injury. SEIFA, Socio-Economic Indexes for Areas.

with temporary frequent attenders, and for adults and children, demonstrate a need to consider different types of interventions. In particular, the cohort of persistent frequent attenders may receive more benefit from case management, and increased continuity of primary care provider ${ }^{49}$ than temporary frequent attenders. Young adults with ongoing frequent attendance related to substance disorders and psychiatric illness may benefit from additional services outside the ED, while among children, older females with neurological conditions (predominantly seizure-related and headaches) could benefit from pathways which reduce the likelihood of admission and result in reduced length of hospital stay. ${ }^{50}$

Our research has shown a complex relationship between ED attendance and hospital admission. Multivariate analysis showed frequent ED attendance was inversely associated with hospital admission, and duration of frequent ED attendance was not associated with hospital admission among adults, suggesting some frequent attenders may be treated and/or managed in a different setting. Highly frequent users do not use other healthcare services proportionally more than (low volume) frequent users, ${ }^{39}$ suggesting highly frequent attenders may use ED's as a main source of care. It is therefore possible that the persistent frequent attender cohort, of which almost half were highly frequent attenders, also use the ED as a main source of care.

The heterogeneity of frequent attenders has contributed to ineffective policy development, with interventions needing to target-specific subgroups. ${ }^{5}$ Similar to evidence in the literature, we identified three vulnerable patient groups at high risk of frequent attendance; those in situations of socioeconomic distress (eg, low income, homelessness, social isolation) $)^{89112151}$; those living with mental health and substance use problems ${ }^{813947}$; and the elderly. ${ }^{52}$ The first two of these groups are more likely to be ongoing frequent attenders, while the latter, elderly group tend to be temporary frequent attenders. Due to the ongoing nature of frequent ED attendance by those with socioeconomic and mental health issues, or both, it is imperative to find cost-effective alternatives. Temporary older frequent attenders are driving increases in ED utilisation and changing the clinical profile of EDs. ${ }^{53-56}$ This group are multimorbid, with complex, ongoing healthcare needs, and required improved identification and management of those at risk of return..$^{52545758}$ To date, hospital-based interventions for these elderly patients have had little effect on ED use, potentially due to their typically short-term nature. However, a systematic review found that interventions in outpatient and primary care/home settings (including geriatric assessment and management and case management) have reduced ED use among this patient cohort. ${ }^{59}$

Our research has shown a complex relationship between ED attendance and hospital admission and found longitudinal ED data investigating ongoing frequent use identifies additional and inflated risk factors. In accordance with the recommendations of Pines et $a l^{33}$ the authors future research agenda includes using data in model development and testing for predicting patients who are at risk of becoming and/or remaining frequent attenders. This will improve generalisability of existing predictive models, which are mostly from the USA, ${ }^{4660} 61$ often have small samples, ${ }^{1160}$ focus on a specific patient sub-group (eg, Medicaid users), ${ }^{46}$ or using inconsistent thresholds for frequent attendance (3, 4 or 10 visits in a year). ${ }^{116061}$

\section{Limitations}

The inclusion of any patients whose with frequent attendance for any 12-month period during the 10-year study period enabled patients to be grouped according to long-term patterns of frequent attendance; however, some temporary and repeat frequent attenders may have 
been classified differently had all participants had equal follow-up time.

Logistic regression models identifying factors associated with frequent attendance used both characteristics of the person (eg, sociodemographics) and their presentations to ED (diagnosis, urgency) throughout the study period, therefore there is confounding between the independent and dependent variables. When developing models to predict future frequent attendance, these would need to use only characteristics prior to a period of frequent attendance. Data quality, data consistency and the amount of missing information (in particular diagnosis) improved over time, which may impact descriptive and modelling results. The effect of missing diagnoses was minimised by modelling a patient's most common diagnostic block over all visits. While hospital insurance and preferred language were imputed using recent data, having a partner was considered more likely to change over the study period so missing cases were excluded from models.

Social variables that may increase the risk of frequent attendance, such as use of primary care services, homelessness or isolation, are not routinely collected. Other factors that may be predictive of frequent attendance, such as patient satisfaction with treatment, and having a regular source of care ${ }^{62}$ were not collected.

We could not link to data on deaths outside of the public hospital system and therefore could not explore reasons for patients discontinuing frequent attendance; however, this is an area of potential future research. Finally, while we included data from metropolitan and rural EDs in one region in Australia, this may not be generalisable to other settings.

\section{CONCLUSIONS}

This study has provided a unique, longitudinal perspective on ED frequent attenders, contrasting the demographic and diagnostic profile of temporary, repeat and persistent frequent attenders. The distinction between temporary and ongoing frequently attending cohorts should be used when describing frequent attenders, and to inform appropriate interventions and better direct health resources.

\footnotetext{
Author affiliations

${ }^{1}$ Centre for Health Research Illawarra Shoalhaven Population, Faculty of Business, University of Wollongong, Wollongong, New South Wales, Australia

${ }^{2}$ Planning Performance Management and Information Unit, Illawarra Shoalhaven Local Health District, Wollongong, New South Wales, Australia

${ }^{3}$ Planning and Strategic Commissioning, Illawarra Shoalhaven Local Health District, Wollongong, New South Wales, Australia

${ }^{4}$ Emergency Medicine, Illawarra Shoalhaven Local Health District, Wollongong, New South Wales, Australia

${ }^{5}$ Australian Health Services Research Institute, Faculty of Business, University of Wollongong, Wollongong, New South Wales, Australia
}

Acknowledgements We would like to thank Sam Allingham, David Webster, Brendan McAlister and Niki Cirillo for reviewing the manuscript, and assistance with accessing data and interpretation. Patients and the public were not involved in the design or conduct of this study.

Contributors LL carried out analysis, interpretation and drafted the manuscript. VW-W and KL assisted with interpretation of the data and assisted with drafting and reviewing the manuscript. RZ, JM, TC and WT contributed to interpretation of the data and reviewed the manuscript. KE was responsible for the study conception and contributed to interpretation of the data and reviewed the manuscript. All authors revised the paper and gave approval for the final version to be published and are accoutnable for all aspects of the work.

Funding The authors acknowledge the Illawarra Health Information Platform (IHIP) research partnership established between the Illawarra Shoalhaven Local Health District (ISLHD) and the University of Wollongong, with ISLHD providing funding support and the data used in this study, and the NSW Ministry of Health who authorised the data release.

Competing interests None declared.

Patient consent for publication Not required.

Ethics approval Ethical approval for establishment of IHIP's non-identifiable databank, including the ISLHD administrative data, was obtained from the University of Wollongong and Illawarra Shoalhaven Local Health District 's Health and Medical Human Research Ethics Committee (HREC) on 14 November 2016 (Ethics number: 2016/306). The CHRISP Executive Steering Committee also approved this study.

Provenance and peer review Not commissioned; externally peer reviewed.

Data sharing statement Additional materials are available in the supplementary appendix, the dataset was extracted from the Illawarra Health Information Platform.

Open access This is an open access article distributed in accordance with the Creative Commons Attribution Non Commercial (CC BY-NC 4.0) license, which permits others to distribute, remix, adapt, build upon this work non-commercially, and license their derivative works on different terms, provided the original work is properly cited, appropriate credit is given, any changes made indicated, and the use is non-commercial. See: http://creativecommons.org/licenses/by-nc/4.0/.

\section{REFERENCES}

1. Fuda KK, Immekus R. Frequent users of Massachusetts emergency departments: a statewide analysis. Ann Emerg Med 2006;48:16. e1-16.e8

2. Bernstein SL. Frequent emergency department visitors: the end of inappropriateness. Ann Emerg Med 2006;48:18-20.

3. Malone RE. Almost 'like family': emergency nurses and 'frequent flyers'. J Emerg Nurs 1996;22:176-83.

4. Lucas RH, Sanford SM. An analysis of frequent users of emergency care at an urban university hospital. Ann Emerg Med 1998;32:563-8.

5. LaCalle E, Rabin E. Frequent users of emergency departments: the myths, the data, and the policy implications. Ann Emerg Med 2010;56:42-8.

6. Locker TE, Baston S, Mason SM, et al. Defining frequent use of an urban emergency department. Emerg Med J 2007;24:398-401.

7. Malone RE. Whither the almshouse? Overutilization and the role of the emergency department. J Health Polit Policy Law 1998;23:795-832.

8. Mandelberg JH, Kuhn RE, Kohn MA. Epidemiologic analysis of an urban, public emergency department's frequent users. Acad Emerg Med 2000;7:637-46.

9. Sun BC, Burstin HR, Brennan TA. Predictors and outcomes of frequent emergency department users. Acad Emerg Med 2003;10:320-8.

10. Pope D, Fernandes CM, Bouthillette F, et al. Frequent users of the emergency department: a program to improve care and reduce visits. CMAJ 2000;162:1017-20.

11. Andrén KG, Rosenqvist U. An ecological study of the relationship between risk indicators for social disintegration and use of a somatic emergency department. Soc Sci Med 1987;25:1121-7.

12. Spillane LL, Lumb EW, Cobaugh DJ, et al. Frequent users of the emergency department: can we intervene? Acad Emerg Med 1997;4:574-80.

13. Althaus F, Paroz S, Hugli O, et al. Effectiveness of interventions targeting frequent users of emergency departments: a systematic review. Ann Emerg Med 2011;58:41-52.

14. Moe J, Kirkland SW, Rawe E, et al. Effectiveness of interventions to decrease emergency department visits by adult frequent users: a systematic review. Acad Emerg Med 2017;24:40-52. 
15. Shumway M, Boccellari A, O'Brien K, et al. Cost-effectiveness of clinical case management for ED frequent users: results of a randomized trial. Am J Emerg Med 2008;26:155-64.

16. Skinner J, Carter L, Haxton C. Case management of patients who frequently present to a Scottish emergency department. Emerg Med J 2009;26:103-5.

17. Phillips GA, Brophy DS, Weiland TJ, et al. The effect of multidisciplinary case management on selected outcomes for frequent attenders at an emergency department. Med J Aust 2006;184:602-6.

18. Okin RL, Boccellari A, Azocar F, et al. The effects of clinical case management on hospital service use among ED frequent users. Am J Emerg Med 2000;18:603-8.

19. Olsson $M$, Hansagi $H$, Tomson $Y$, et al. Individualised care plans-a feasible way to improve care for frequent users of the emergency department. Socialmed Tidskr 2004;1:122-9.

20. Hansagi $H$, Olsson $M$, Hussain $A$, et al. Is information sharing between the emergency department and primary care useful to the care of frequent emergency department users? Eur J Emerg Med 2008;15:34-9.

21. Krieg C, Hudon C, Chouinard MC, et al. Individual predictors of frequent emergency department use: a scoping review. BMC Health Serv Res 2016;16:594.

22. Brunero S, Fairbrother G, Lee S, et al. Clinical characteristics of people with mental health problems who frequently attend an Australian emergency department. Aust Health Rev 2007;31:462-70.

23. Quilty S, Shannon G, Yao A, et al. Factors contributing to frequent attendance to the emergency department of a remote Northern Territory hospital. Med J Aust 2016;204:111.

24. Blank FS, Li H, Henneman PL, et al. A descriptive study of heavy emergency department users at an academic emergency department reveals heavy ED users have better access to care than average users. J Emerg Nurs 2005;31:139-44.

25. Ruger JP, Richter CJ, Spitznagel EL, et al. Analysis of costs, length of stay, and utilization of emergency department services by frequent users: implications for health policy. Acad Emerg Med 2004;11:1311-7.

26. Williams ER, Guthrie E, Mackway-Jones K, et al. Psychiatric status, somatisation, and health care utilization of frequent attenders at the emergency department: a comparison with routine attenders. $J$ Psychosom Res 2001;50:161-7.

27. Lim SF, Wah W, Pasupathi Y, et al. Frequent attenders to the ED: patients who present with repeated asthma exacerbations. Am J Emerg Med 2014;32:895-9.

28. Dent AW, Phillips GA, Chenhall AJ, et al. The heaviest repeat users of an inner city emergency department are not general practice patients. Emerg Med Aust 2003;15:322-9.

29. Markham D, Graudins A. Characteristics of frequent emergency department presenters to an Australian emergency medicine network. BMC Emerg Med 2011;11:21.

30. Palmer E, Leblanc-Duchin D, Murray J, et al. Emergency department use: is frequent use associated with a lack of primary care provider? Can Fam Physician 2014;60:e223-9.

31. Reeder T, Locascio E, Tucker J, et al. ED utilization: the effect of changing demographics from 1992 to 2000. Am J Emerg Med 2002;20:583-7.

32. Dinh MM, Berendsen Russell S, Bein KJ, et al. Trends and characteristics of short-term and frequent representations to emergency departments: A population-based study from New South Wales, Australia. Emerg Med Australas 2016;28:307-12.

33. Pines JM, Asplin BR, Kaji AH, et al. Frequent users of emergency department services: gaps in knowledge and a proposed research agenda. Acad Emerg Med 2011;18:e64-e69.

34. Illawarra Shoalhaven Local Health District. About us. http://www. islhd.health.nsw.gov.au/about_us.asp (Accessed 13 Jul 2017).

35. Bureau of Health Information. Hospital Quarterly: Performance of NSW public hospitals, January to March 2013. Sydney (NSW): Emergency Departments, 2013.

36. Siminski P, Bezzina AJ, Lago LP, et al. Primary care presentations at emergency departments: rates and reasons by age and sex. Aust Health Rev 2008;32:700-9.

37. Bureau of Health Information. Patient Perspectives - Exploring aspects of integration for hospital patients. Volume 2, Emergency Department Patients. Sydney (NSW): BHI, 2015.
38. Jacob R, Wong ML, Hayhurst C, et al. Designing services for frequent attenders to the emergency department: a characterisation of this population to inform service design. Clin Med 2016;16:325-9.

39. Doupe MB, Palatnick W, Day S, et al. Frequent users of emergency departments: developing standard definitions and defining prominent risk factors. Ann Emerg Med 2012;60:24-32.

40. Cook LJ, Knight S, Junkins EP, et al. Repeat patients to the emergency department in a statewide database. Acad Emerg Med 2004;11:256-63.

41. Randall DA, Lujic S, Leyland $\mathrm{AH}$, et al. Statistical methods to enhance reporting of Aboriginal Australians in routine hospital records using data linkage affect estimates of health disparities. Aust N Z J Public Health 2013;37:442-9.

42. Pink B. Census of Population and Housing: Socio-Economic Indexes for Areas (SEIFA), Australia, 2011. Technical Paper. Canberra: Australian Government, 2011:54-8.

43. Australian Consortium for Classification Development. The International Statistical Classification of Diseases and Related Health Problems, tenth revision, Australian modification (ICD-10-AM/ACHI/ ACS). Tenth ed. Darlinghurst, NSW: Independent Hospital Pricing Authority, 2017.

44. Independent Hospital Pricing Authority. URG Grouper User Guide (Text) Activity Based Funding Version 1.4.4. Darlinghurst, NSW: Independent Hospital Pricing Authority, 2016.

45. SAS Institute Inc. Base SAS 9.4 Procedures Guide Cary. NC: SAS Institute Inc, 2013.

46. Billings J, Raven MC. Dispelling an urban legend: frequent emergency department users have substantial burden of disease. Health Aff 2013;32:2099-108.

47. Kennedy D, Ardagh M. Frequent attenders at Christchurch Hospital's Emergency Department: a 4-year study of attendance patterns. N Z Med J 2004;117:U871.

48. Kne T, Young R, Spillane L. Frequent ED users: patterns of use over time. Am J Emerg Med 1998;16:648-52.

49. Huntley $A$, Lasserson $D$, Wye $L$, et al. Which features of primary care affect unscheduled secondary care use? A systematic review. BMJ Open 2014;4:e004746.

50. lyer PM, McNamara PH, Fitzgerald M, et al. A seizure care pathway in the emergency department: preliminary quality and safety improvements. Epilepsy Res Treat 2012;2012:1-7.

51. Hunt KA, Weber EJ, Showstack JA, et al. Characteristics of frequent users of emergency departments. Ann Emerg Med 2006;48:1-8.

52. Arendts G, Lowthian J. Demography is destiny: an agenda for geriatric emergency medicine in Australasia. Emerg Med Australas 2013;25:271-8.

53. Aboagye-Sarfo P, Mai Q, Sanfilippo FM, et al. Growth in Western Australian emergency department demand during 2007-2013 is due to people with urgent and complex care needs. Emerg Med Australas 2015;27:202-9.

54. Lowthian JA, Curtis AJ, Jolley DJ, et al. Demand at the emergency department front door: 10-year trends in presentations. Med J Aust 2012;196:128-32.

55. Lowthian JA, Curtis AJ, Cameron PA, et al. Systematic review of trends in emergency department attendances: an Australian perspective. Emerg Med J 2011;28:373-7.

56. Xu KT, Nelson BK, Berk S. The changing profile of patients who used emergency department services in the United States: 1996 to 2005. Ann Emerg Med 2009;54:805-10.

57. Legramante JM, Morciano L, Lucaroni F, et al. Frequent use of emergency departments by the elderly population when continuing care is not well established. PLoS One 2016;11:e0165939.

58. McCusker J, Karp I, Cardin S, et al. Determinants of emergency department visits by older adults: a systematic review. Acad Emerg Med 2003;10:1362-70.

59. McCusker J, Verdon J. Do geriatric interventions reduce emergency department visits? A systematic review. J Gerontol A Biol Sci Med Sci 2006;61:53-62

60. Rask KJ, Williams MV, McNagny SE, et al. Ambulatory health care use by patients in a public hospital emergency department. J Gen Intern Med 1998;13:614-20.

61. Okuyemi KS, Frey B. Describing and predicting frequent users of an emergency department. J Assoc Acad Minor Phys 2001;12:119-23.

62. Hansagi H, Olsson M, Sjöberg S, et al. Frequent use of the hospital emergency department is indicative of high use of other health care services. Ann Emerg Med 2001;37:561-7. 